\title{
Synthesis and Catalysis
}

\author{
Karl Gademann*, Andreas Pfaltz*, Hermann A. Wegner*, Helma Wennemers*, Wolf-D. Woggon*, \\ and Antoinette Chougnet*
}

\begin{abstract}
Research projects of the Department of Chemistry, University of Basel are reviewed ranging from the synthesis of complex natural products to the development of metalorganic catalysts and organocatalysts
\end{abstract}

Keywords: Copper - Cyanobacteria - Domino reactions · Gold · Iridium - Henry reactions ·

Hydrogen transfer reactions · Ruthenium - Palladium - Peptides · Prolin · Organocatalysts · Sporolides .

Terpenes · Vitamin E

\section{Syntheses of Natural Products}

\section{Karl Gademann}

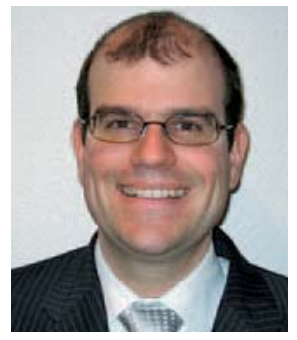

One line of research in the Gademann lab is directed towards the development of novel strategies and tactics in organic synthesis, and in particular, to achieve concise syntheses of natural products based on biogenetic proposals. Targets are selected either due to their complex architecture challenging current synthetic methodology or the choice is made based on interesting biological activity related to other research activities in the group. In this context the anguinomycins C (1) and D (2) were prepared. These compounds are inhibitors of protein transporters shuttling cargo proteins out of the nucleus. ${ }^{[1,2]}$ Key steps of the syntheses of $\mathbf{1}$ and $\mathbf{2}$ include a Jacobsen $\mathrm{Cr}$ (III)-mediated hetero
Diels-Alder reaction, a Negishi cross coupling reaction proceeding under inversion, and extensive use of the Seebach version of the Evans auxiliary (Fig. 1).

Regarding marine metabolites, a research program was initiated ${ }^{[3,4]}$ towards the total synthesis of sporolides A (3) and B (4), complex heptacyclic metabolites displaying a highly oxygenated heptacyclic framework (Fig. 2). The enantioselective preparation of the quinone fragment has been achieved ${ }^{[4]}$ and a route following a biosynthetic proposal via an enediyne precursor and Bergman cyclization has so far not been successful.[3] A target of terpene natural origin is represented by cyrneine A (5), which has been shown to display neuritogenic properties. ${ }^{[5]}$

In addition, Karl Gademann's group developed several routes to natural products based on biosynthetic considerations.
For example, the preparation of the cyanobacterial siderophore anachelin (6), $\left.{ }^{6}\right]$ previously achieved by Te-mediated aza annulations ${ }^{[7-9]}$ was carried out using the enzyme tyrosinase (Scheme 1). By this route $^{[10]}$ heterofunctionalization of the aromatic group of a suitably protected tyrosine amine precursor 7 was carried out, and concomitant hydroxylation, amination and ring closure to the anachelin chromophore 8 was achieved in quantitative yield. ${ }^{[10]}$ This transformation exemplifies the power of enzymes in biomimetic transformations on a preparative scale.

A biomimetic approach was also used for the synthesis of (-)-taiwaniaquinone H (9).[11,12] Hence, a suitably oxidized abietane or ferruginol precursor such as 10 was smoothly transformed to the rearranged $\mathrm{C}_{19}$ intermediate $\mathbf{1 1}$ upon exposure to base and under loss of $\mathrm{CO}_{2}$ (Scheme 2). This compound was then converted to 9 by a protecting group-free synthesis. For mechanistic details the interested reader is referred to the original publications. ${ }^{[11,12]}$

${ }^{*}$ Correspondence: Prof. K. Gademann

Department of Chemistry

St. Johanns-Ring 19

$\mathrm{CH}-4056$ Basel

E-mail: karl.gademann@unibas.ch

${ }^{*}$ Prof. A. Pfaltz

Department of Chemistry

St. Johanns-Ring 19

$\mathrm{CH}-4056$ Basel

E-mail: andreas.pfaltz@unibas.ch

*Dr. H. A. Wegner

Department of Chemistry

St. Johanns-Ring 19

$\mathrm{CH}-4056$ Basel

E-mail: Hermann.wegner@unibas.ch

*Prof. H. Wennemers

Department of Chemistry

St. Johanns-Ring 19

$\mathrm{CH}-4056$ Basel

E-mail: helma.wennemers@unibas.ch

${ }^{*}$ Prof. W.-D. Woggon, Prof. A. Chougnet

Department of Chemistry

St. Johanns-Ring 19

$\mathrm{CH}-4056$ Basel

E-mail: wolf-d.woggon@unibas.ch,

antoinette.chougnet@unibas.ch
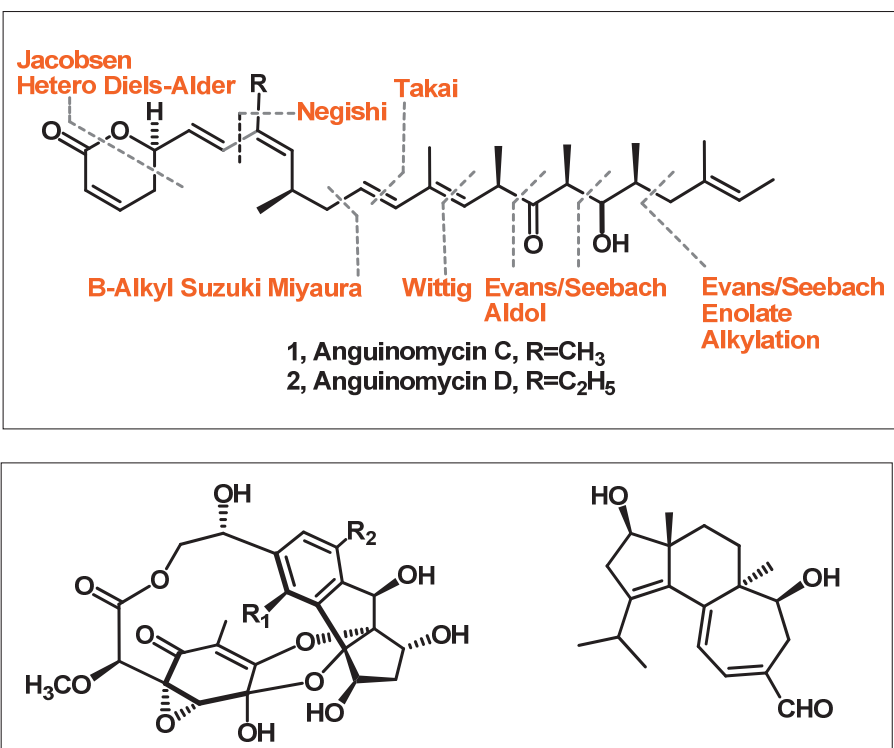

Fig. 1. Synthetic strategy employed for the synthesis of Anguinomycin $\mathrm{C}$.

Fig. 2. Synthetic targets of the Gademann group. 

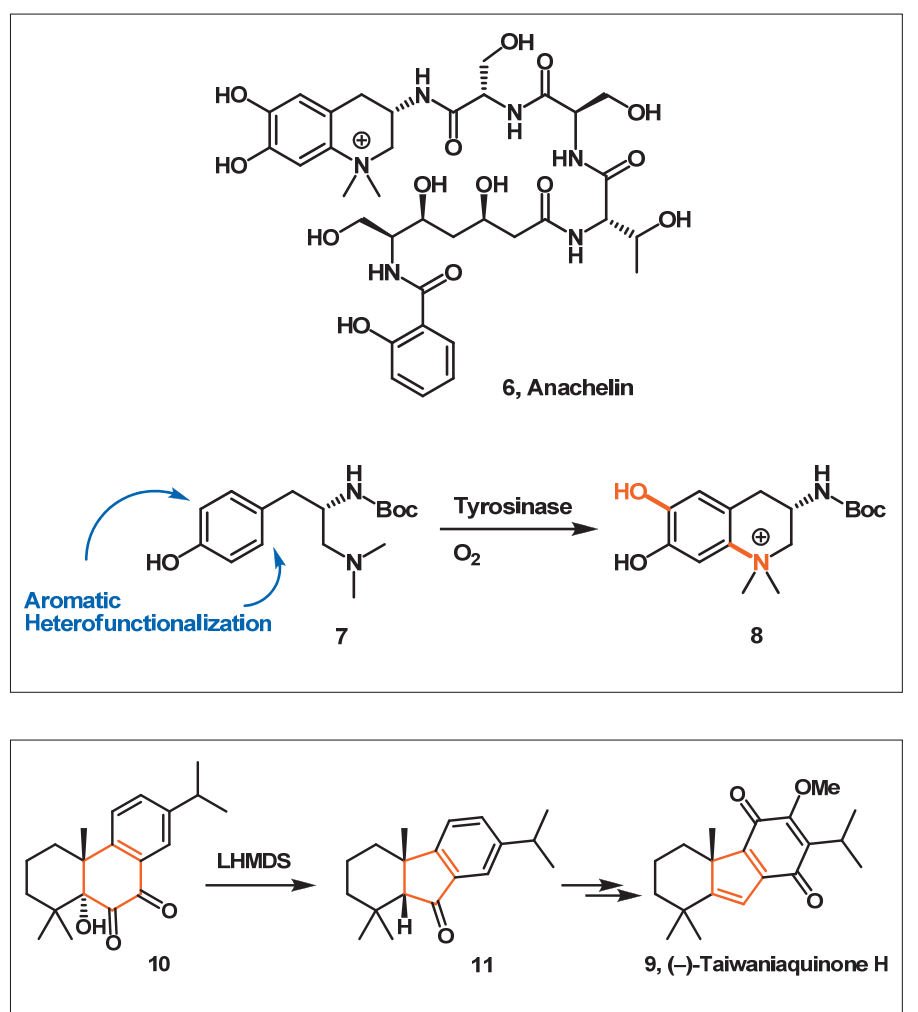

[1] S. Bonazzi, S. Güttinger, I. Zemp, U. Kutay, K. Gademann, Angew. Chem. Int. Ed. 2007, 46, 8707.

[2] S. Bonazzi, O. Eidam, S. Güttinger, J.-Y. Wach, I. Zemp, U. Kutay, K. Gademann, J. Am. Chem. Soc. 2010, 132, 1432

[3] S. Bonazzi, M. Binaghi, C. Fellay, J.-Y. Wach, K. Gademann, Synthesis 2010, 631.

[4] J.-Y. Wach, K. Gademann, Synlett 2009, 2849.

[5] M. C. Marcotullio, R. Pagiott, F. Maltese, Y. Obara, T. Hoshino, N. Nakahata, M. Curini, Planta Med. 2006, 72, 819.

[6] K. Gademann, C. Portmann, Curr. Org. Chem. 2008, 12, 326.
Scheme 2. Biomimetic ring contraction leading to (-)-taiwaniaquinone

$\mathrm{H}(9)$.

Scheme 1. Enzymecatalyzed preparation of 8 , the alkaloid fragment of anachelin (6).

7] A. K. Lawrence, K. Gademann, Synthesis 2008 , 331 .

[8] K. Gademann, Y. Bethuel, Angew. Chem. Int. Ed. 2004, 43, 3327.

[9] K. Gademann, Y. Bethuel, Org. Lett. 2004, 6, 4707.

[10] K. Gademann, Y. Bethuel, H. H. Locher, C. Hubschwerlen, J. Org. Chem. 2007, 72, 8361.

11] C. K. Jana, R. Scopelliti, K. Gademann, Chem. Eur. J. 2010, 16, 7692

[12] C. K. Jana, R. Scopelliti, K. Gademann, Synthesis 2010, 2223.

\section{Design and Screening of Chiral Catalysts}

\section{Andreas Pfaltz}

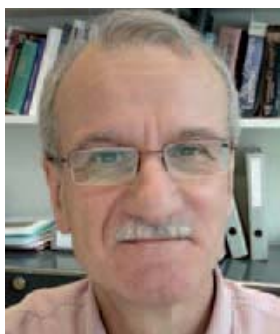

The Pfaltz group

has been active in the development of chiral ligands and metal catalysts for many years. Starting point of their research were the semicorrins which were introduced in the mid 1980s (Fig. 1). ${ }^{[1]}$ Key features of the semicorrin structure are a conformationally rigid $\mathrm{C}_{2}$-symmetric ligand scaffold, with two substituents in close proximity to the coordination sphere that have a strong and direct influence on a metal-catalyzed process.

The high enantioselectivities induced by semicorrins in the copper-catalyzed cyclopropanation and cobalt-catalyzed conjugate reduction of $\alpha, \beta$-unsaturated carboxylic esters and amides prompted the development of various structurally related ligands in the Pfaltz lab as well as in many other research groups. Bisoxazolines, now known as BOX ligands, have found an impressive number of applications in asymmetric catalysis and today are regarded as privileged ligands. ${ }^{[2]}$ The most recent addition to the bisoxazolines are the BoraBOX ligands, which were successfully applied in several metal-catalyzed reactions. ${ }^{[3]}$

$\mathrm{C}_{2}$-symmetric bidentate ligands have dominated in asymmetric catalysis for a long time. Although $\mathrm{C}_{2}$-symmetry offers a number of advantages, for certain reactions non-symmetrical ligands with two different coordinating groups should allow more effective enantiocontrol than $\mathrm{C}_{2}$-symmetric ligands. Transition metalcatalyzed allylic substitution via symmetric allyl intermediates is an example, see the Pd complex in Fig. 1. In this reaction, the regioselectivity of nucleophilic attack determines the ratio of the two enantiomeric products. If the metal center is coordinated by two electronically different heteroatoms, the two allylic termini become electronically non-equivalent and thus are expected to display different reactivity. Therefore, non-symmetric ligands with two different coordinating atoms such as $\mathrm{P}$ and $\mathrm{N}$ should, in principle, allow more effective regiocontrol than $\mathrm{C}_{2}$-symmetric ligands.

Indeed, palladium complexes with phosphinooxazolines (PHOX ligands), developed independently by the groups of Helmchen, J. M. J. Williams, and Pfaltz, turned out to be efficient enantioselective catalysts for Pd-catalyzed allylic substitutions. ${ }^{[4]}$ Because of their modular structure, a wide variety of ligands with differently substituted oxazoline rings, different phosphine groups and different backbones can be readily prepared. In this way the ligand structure can be sterically and electronically tuned for a specific application.

Chiral oxazoline-based P,N-ligands, which have a complementary application range to the P,P-ligands developed by Trost, ${ }^{[5]}$ have significantly enhanced the scope of enantioselective allylic substitution. Further studies have shown that PHOX and related P,N-ligands can induce high enantioselectivities in numerous other metal-catalyzed reactions such as Heck reactions, 1,4-additions of organozinc reagents to enones, and $\mathrm{Ag}(\mathrm{I})$-catalyzed [3+2] cycloadditions of azomethine ylides. ${ }^{[4,6]}$

One of the major areas of current research in the Pfaltz group is asymmetric hydrogenation, which is one of the most widely used, most reliable catalytic methods for the preparation of optically active compounds. ${ }^{[7]}$ High enantioselectivity, low catalyst loadings, essentially quantitative yields, and mild conditions are attractive features of this transformation. Since the early 1970s, when the well-known L-Dopa process was established at Monsanto, ${ }^{77 \mathrm{c}]}$ hydrogenation has played a dominant role in industrial asymmetric catalysis. Many chiral phosphine ligands are available today, which induce very high enantioselectivity in rhodium- and ruthenium-catalyzed hydrogenations of suitably functionalized olefins. Nevertheless, the application range of $\mathrm{Rh}$ and $\mathrm{Ru}$ catalysts is limited, as they require the presence of a polar functional group next to the $\mathrm{C}=\mathrm{C}$ bond, which can coordinate to the metal center. With unfunctionalized olefins, these catalysts generally show low reactivity and unsatisfactory enantioselectivity.

In the course of their work on PHOX ligands, the Pfaltz group discovered that iridium complexes with chiral P,N-ligands can overcome these limitations. ${ }^{[8]}$ In contrast to $\mathrm{Rh}$ and $\mathrm{Ru}$ catalysts, they 


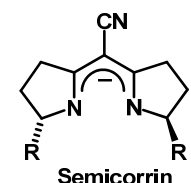

Semicorrin<smiles>[R]C1CCC(N([R])C2=NC([R])CC2)=N1</smiles>
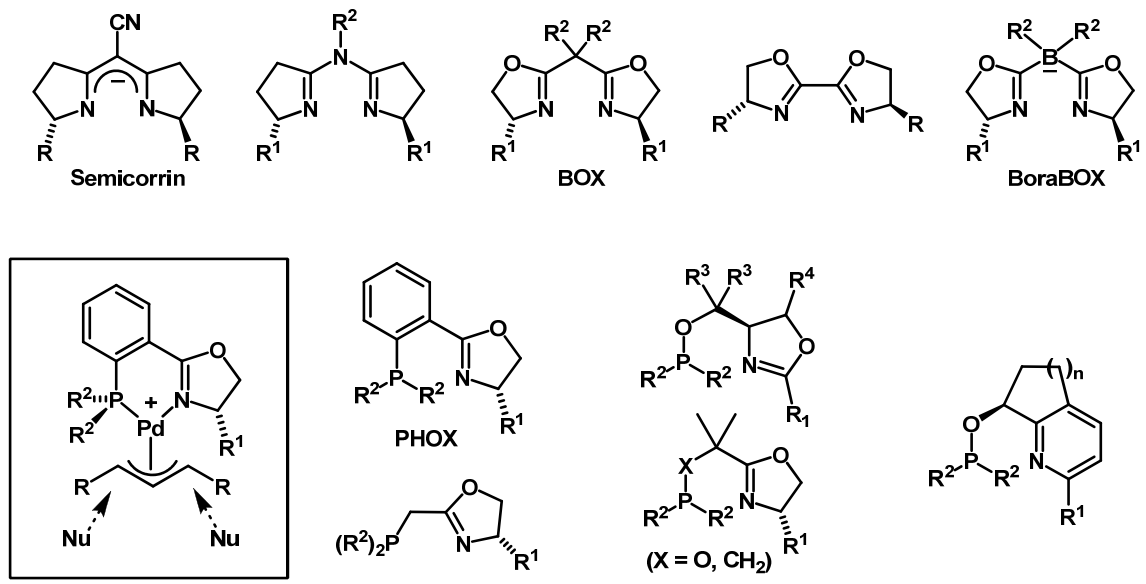

Fig. 1. Ligands and complexes for various enantioselective catalytic reactions.

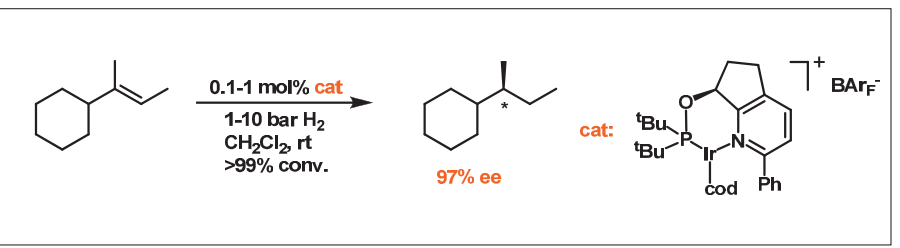

Scheme 1. Enantio selective hydrogenation of unfunctionalized double bonds do not require a coordinating polar group next to the $\mathrm{C}=\mathrm{C}$ bond. Initial experiments with cationic PHOX complexes showed that these catalysts were highly active in the hydrogenation of unfunctionalized triand even tetrasubstituted olefins. In this respect, they resembled the Crabtree catalyst, $\left[\left(\mathrm{Cy}_{3} \mathrm{P}\right)\right.$ (pyridine) $\left.\operatorname{Ir}(\mathrm{COD})\right] \mathrm{PF}_{6}(\mathrm{Cy}=$ cyclohexyl), ${ }^{[9]}$ which provided the stimulus for this work. The counter ion plays an important role in this process. With $\mathrm{BAr}_{\mathrm{F}} \quad$ (tetrakis[3,5-bis(trifluoromethyl) phenyl]borate) TONs of $>5000$ could be achieved, whereas the corresponding hexafluorophosphate salt usually lost catalytic activity after 40-200 turnovers. Tetrafluoroborates and triflates showed only very low activity while halides were completely inactive.

An extensive search for other P,N-ligands (for examples, see Fig. 1) led to a diverse set of new Ir complexes, which have considerably expanded the scope of enantioselective hydrogenation to many different classes of unfunctionalized as well as functionalized olefins. ${ }^{[8 b]}$ Several other research groups have also become interested in Ir-catalyzed asymmetric hydrogenation and have reported additional oxazolineand pyridine-derived P,N-ligands. ${ }^{[10,11]}$

For a long time, purely alkyl-substituted olefins could not be hydrogenated with satisfactory enantioselectivity. However, bicyclic pyridine-based ligands, finally led to a breakthrough (Scheme 1).[12] The potential of these catalysts was demonstrated with the highly enantio- and diastereoselective introduction of the two stereocenters of the side chain of vitamin $\mathrm{E}$ by simul-

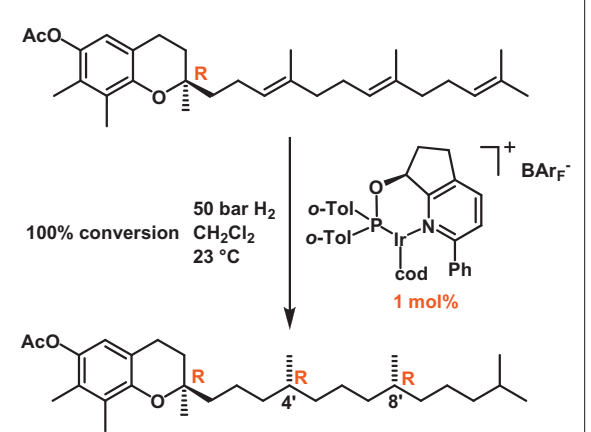

99\% RRR; < $0.3 \%$ RRS; $<0.3 \%$ RSR; $<0.4 \%$ RSS

Scheme 2. Enantioselective hydrogenation of toctrienyl acetate.

taneous hydrogenation of three $\mathrm{C}=\mathrm{C}$ bonds (Scheme 2).[11a]

Iridium complexes with pyridine-phosphinite ligands also proved to be active catalysts for the asymmetric hydrogenation of a wide range of functionalized olefins including $\alpha, \beta$-unsaturated carboxylic esters and ketones, as well as imines, furans and indoles. ${ }^{[10-13]}$ Another long-standing problem that was recently solved, was the hydrogenation of tetrasubstituted olefins, which were known to be notoriously unreactive substrates. Certain iridium P,N complexes showed unexpectedly high activity and allowed the hydrogenation of a range of tetrasubstituted olefins with high enantioselectivity. ${ }^{[14]}$

Another current project of the Pfaltz group focuses on the development of new screening methods for chiral catalysts.
Parallel screening by product analysis of individual reactions has potential pitfalls, because catalytically active impurities or competing unselective background reactions can strongly affect the enantiomeric purity of the product. Such problems would be avoided if the catalyst's ability for enantiodiscrimination could be determined directly from examining catalystreactant intermediates rather than by product analysis. The feasibility of this concept was recently demonstrated for the palladium-catalyzed kinetic resolution of allylic esters, using electrospray ionization mass spectrometry (ESI-MS) as an analytical tool (Fig. 2). ${ }^{[15]}$

ESI-MS which is selective for charged species allows the detection of ionic intermediates in low concentration in the presence of a large excess of neutral species. In Pd-catalyzed allylic substitutions, the first step, formation of Pd-allyl complexes $\mathbf{X}$ and $\mathbf{Y}$ is fast, while the second step, nucleophilic addition to the allyl system is slower and turnover-limiting. The ratio $\mathbf{A}: \mathbf{B}$ reflects the catalyst's ability to discriminate between the two enantiomeric substrates $\mathbf{A}$ and $\mathbf{B}$ (Fig. 2). In order to distinguish $\mathbf{X}$ and $\mathbf{Y}$ by mass spectrometry, they were labeled with two different alkyl groups at the para position of the aryl group ( $\mathrm{Ar}=$ 4-methylphenyl in A and 4-ethylphenyl in B). Accordingly, the signals of $\mathbf{X}$ and $\mathbf{Y}$ appear at different positions in the mass spectrum and their ratio can be determined by integration. Because the para-alkyl substituents are too remote from the reactive part of the molecule to have a notable influence on the reaction, the same selectivity is observed as for the parent enantiomers $\mathbf{A}$ and $\mathbf{B}$ with $\mathrm{Ar}=$ phenyl.

When an equimolar mixture of the two quasienantiomers was treated with an achiral Pd catalyst and the anion of diethyl ethylmalonate as the nucleophile, the ESI-MS showed the expected signals corresponding to the allyl intermediates $\mathbf{X}$ and $\mathbf{Y}$ with the characteristic isotope distribution of palladium. As anticipated for an achiral catalyst, the two signal groups had the same intensity. The reaction with a chiral, enantiomerically pure catalyst derived from ligand $\mathbf{L}^{*}$ showed a strong bias toward one of the two quasienantiomers $(\mathbf{X}: \mathbf{Y}=9: 91)$. This ratio is equivalent to the selectivity factor of this kinetic resolution. Experiments with numerous other ligands showed that the ratios obtained by ESI-MS correlated very well with the selectivity factors determined by kinetic analysis of preparative reactions.

Screening by ESI-MS is fast and operationally simple, as it does not require work-up or purification steps and only minimal amounts of substrate are needed. Moreover, mixtures of catalysts with different molecular masses can be screened 


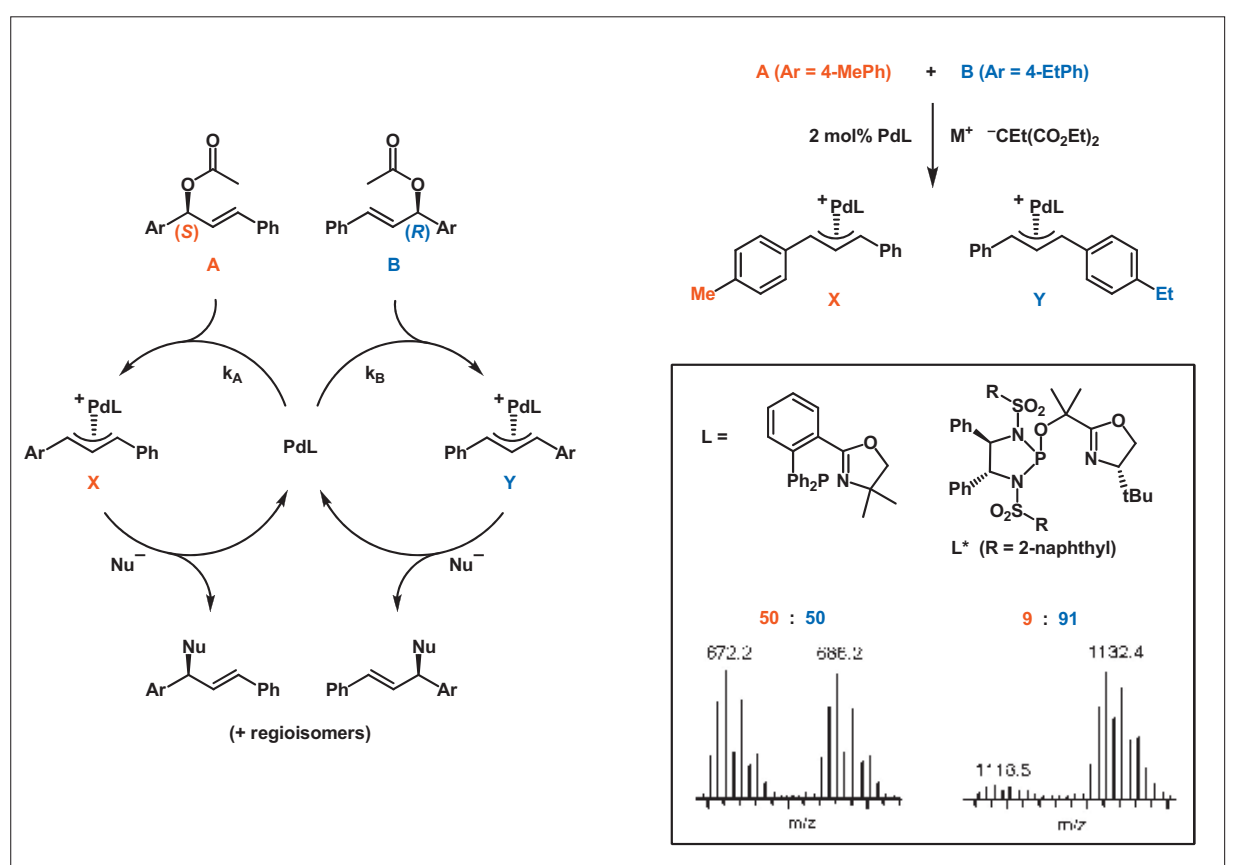

Fig. 2. Palladium complex-catalyzed kinetic resolution of allylic esters.

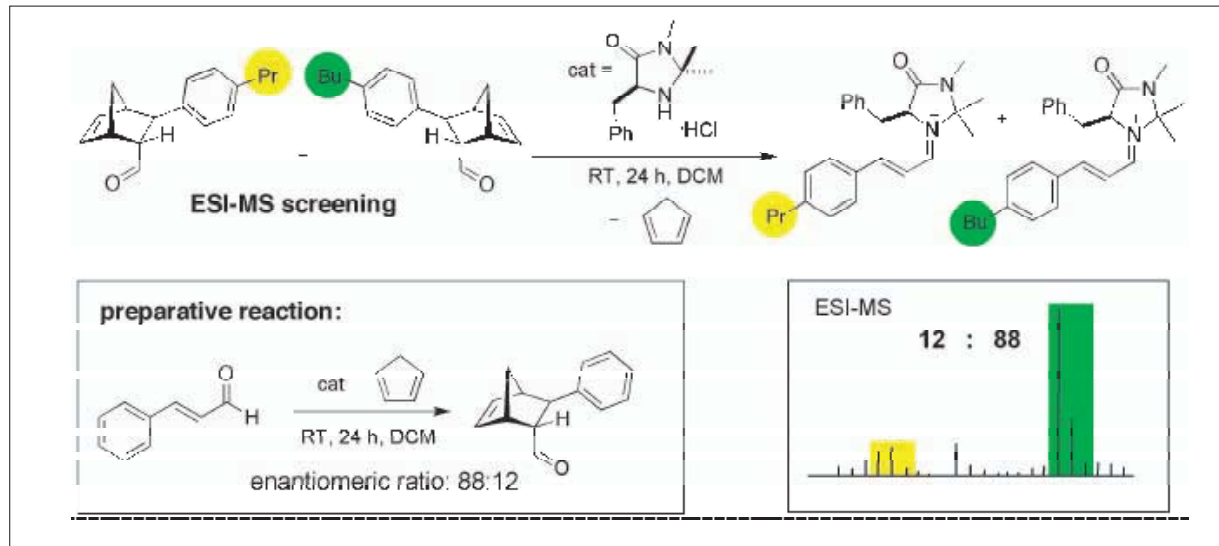

Fig. 3. ESI-MS-screening of organocatalysts for enantioselective Diels-Alder reactions.

simultaneously, which is not possible with methods relying on product analysis. In this way catalyst libraries prepared in one batch by combinatorial methods can be screened without the need to synthesize and purify the catalysts individually. ${ }^{[15 b]}$

In principle, the method cannot be applied to enantioselective transformations of prochiral substrates. However, the corresponding back reaction leading from the two enantiomeric products to the prochiral educt can proceed by kinetic resolution with a chiral catalyst. Therefore, if conditions for catalyzing the back reaction are found, ESI-MS screening becomes possible, starting from quasienantiomeric products. According to the principle of microscopic reversibility the transition states of the forward and backward reaction are identical. Consequently the enantioselectivity determined for the back reaction will be the same as the enantioselectivity of the forward reaction. The feasibility of
[7] a) J. M. Brown, 'Hydrogenation of Functionalized Carbon-Carbon Double Bonds', in 'Comprehensive Asymmetric Catalysis'; Eds E. N. Jacobsen A. Pfaltz, Y. Yamamoto, Springer, Berlin, 1999; Vol. I, Chapter 5.1; b) R. Noyori, Angew. Chem. Int. Ed. 2002, 41, 2008; c) W. S. Knowles, Angew. Chem. Int. Ed. 2002, 41 1998; d) 'Asymmetric Catalysis on Industrial Scale', Eds H.-U. Blaser, E. Schmidt, WileyVCH, Weinheim, 2004.

[8] a) A. Lightfoot, P. Schnider, A. Pfaltz, Angew. Chem. Int. Ed. 1998, 37, 2897; b) Review: S. J. Roseblade, A. Pfaltz, Acc. Chem. Res. 2007, 40, 1402.

[9] R. Crabtree, Acc. Chem. Res. 1979, 12, 331

[10] Recent publications: a) Q.-B. Liu, C.-B. Yu, Y.G. Zhou, Tetrahedron Lett. 2006, 47, 4733; b) Y. Zhu, K. Burgess, J. Am. Chem. Soc. 2008, 130, 8894 ; c) P. Cheruku, J. Diesen, P. G. Andersson, J. Am. Chem. Soc. 2008, 130, 5595; d) M. Dieguez, J. Mazuela, O. Pamies, J. J. Verendel, P. G. Andersson, J. Am. Chem. Soc. 2008, 130, 7208; e) S.-M. Lu, C. Bolm, Angew. Chem. Int. Ed. 2008, 47, 8920; f) W.-J. Lu, Y.-W. Chen, X.L. Hou, Angew. Chem. Int. Ed. 2008, 47, 10133; g) J. Mazuela, J. J. Verendel, M. Coll, Schäffner, A. Börner, P. G. Andersson, O. Pàmies, M. Diéguez, J. Am. Chem. Soc. 2009, 131, 12344; h) J. Zhou, J. W. Ogle, Y. Fan, V. Banphavichit(Bee), Y. Zhu, K. Burgess, Chem. Eur. J. 2010, 13, 7162.

[11] Reviews: a) X. Cui, K. Burgess, Chem. Rev. 2005, 105, 3272; b) T. L. Church, P. G. Andersson, Coord. Chem. Rev. 2008, 252, 513 and [8b].

[12] a) S. Bell, B. Wüstenberg, S. Kaiser, F. Menges, T. Netscher, A. Pfaltz, Science 2006, 311, 643; b) Kaiser, S. P. Smidt, A. Pfaltz, Angew. Chem. Int. Ed. 2006, 45, 5195; c) A. Wang, B. Wüstenberg, A. Pfaltz, Angew. Chem. Int. Ed. 2008, 47, 2298.

[13] a) D. H. Woodmansee, M.-A. Müller, M. Neuburger, A. Pfaltz. Chem. Science 2010, 1, 72; b) A. Baeza, A. Pfaltz, Chem. Eur. J. 2010, 16, 4003; c) A. Baeza, A. Pfaltz, Chem. Eur. J. 2010, 16, 2036; d) M. G. Schrems, A. Pfaltz, Chem. Commun. 2009, 6210; e) A. Baeza, A. Pfaltz, Chem. Eur. J. 2009, 15, 2266.

[14] M. Schrems, E. Neumann, A. Pfaltz, Angew. Chem. Int. Ed. 2007, 46, 8274.

[15] a) C. Markert, A. Pfaltz, Angew. Chem. Int. Ed. 2004, 43, 2498; b) C. Markert, P. Rösel, A. Pfaltz, J. Am. Chem. Soc. 2008, 130, 3234; c) For pioneering studies of ESI-MS-based catalyst screening, see: P. Chen, Angew. Chem. Int. Ed. 2003, 42, 2832

back reaction screening was recently demonstrated for palladium-catalyzed allylic substitutions, ${ }^{[16]}$ copper- and organocatalyzed Diels-Alder reactions (Fig. 3), ${ }^{[17]}$ and organocatalyzed Michael additions. [18]

[1] A. Pfaltz, Acc. Chem. Res. 1993, 26, 339.

[2] G. Desimoni, G. Falta, K. A. Jørgensen, Chem. Rev. 2006, 106, 3561.

[3] a) C. Mazet, V. Köhler, A. Pfaltz, Angew. Chem. Int. Ed. 2005, 31, 4888; b) C. Mazet, S. Roseblade, V. Köhler, A. Pfaltz, Org. Lett. 2006 , 8,$1879 ;$ c) S. Roseblade, A. Pfaltz, Synthesis 2007, 3751; d) V. Köhler, C. Mazet, A. Toussaint, K. Kulicke, D. Häussinger, M. Neuburger, S. Schaffner, S. Kaiser, A. Pfaltz, Chem. Eur. J. 2008, 14, 8530; e) A. Toussaint, A. Pfaltz, Eur. J. Org. Chem. 2008, 4591.

[4] a) G. Helmchen, A. Pfaltz, Acc. Chem. Res. 2000, 33, 336; b) J. M. J. Williams, Synlett 1996, 705 .

[5] B. M. Trost, D. L. Van Vranken, Chem. Rev. 1996, $96,395$.

[6] R. Stohler, F. Wahl, A. Pfaltz, Synthesis 2005, 1431.
[16] a) C. A. Müller, A. Pfaltz, Angew. Chem. Int. Ed. 2008, 47, 3363; b) C. A. Müller, C. Markert, A. M. Teichert, A. Pfaltz, Chem. Commun. 2009, 1607.

[17] A. Teichert, A. Pfaltz, Angew. Chem. Int. Ed. 2008, 47, 3360.

[18] I. Fleischer, A. Pfaltz, Chem. Eur. J. 2010, 16, 95. 


\section{Lewis Acids in Domino Catalysis}

\section{Hermann A. Wegner}

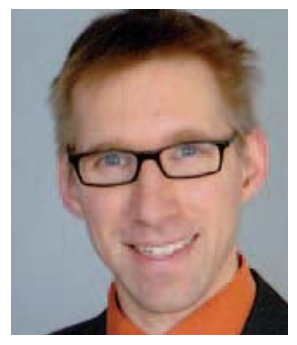

Due to their efficiency and atom economy domino reactions have become very popular in organic synthesis. ${ }^{[1]}$ The group of $\boldsymbol{H}$. A. Wegner is focusing on the development of catalytic domino reactions such as the Au-catalyzed cyclization of alkynyl aryl ester to coumarins. [2] In this reaction the Au-catalyst reacts as a $\pi$-Lewis acid. However, $\mathrm{Au}(\mathrm{III})$ is also capable of promoting an oxidative coupling reaction. ${ }^{[3]}$ If the cyclization of $\mathbf{1}$ is run with $50 \mathrm{~mol} \%$ of Au-catalyst, $32 \%$ of the dimerized product $\mathbf{3}$ can be isolated (Scheme 1).

In this process $\mathrm{Au}(\mathrm{III})$ is reduced to $\mathrm{Au}(\mathrm{I})$ ultimately yielding $\mathrm{Au}(\mathrm{O})$ that is not catalytic active for the oxidative coupling reaction (Scheme 2). In order to accomplish this reaction in a catalytic manner a suitable oxidant had to be found. After an extensive screening a combination of $\mathrm{HAuCl}_{4}$ and $t \mathrm{BuOOH}$ was identified to obtain the desired dimeric coumarins. ${ }^{[4]}$ This
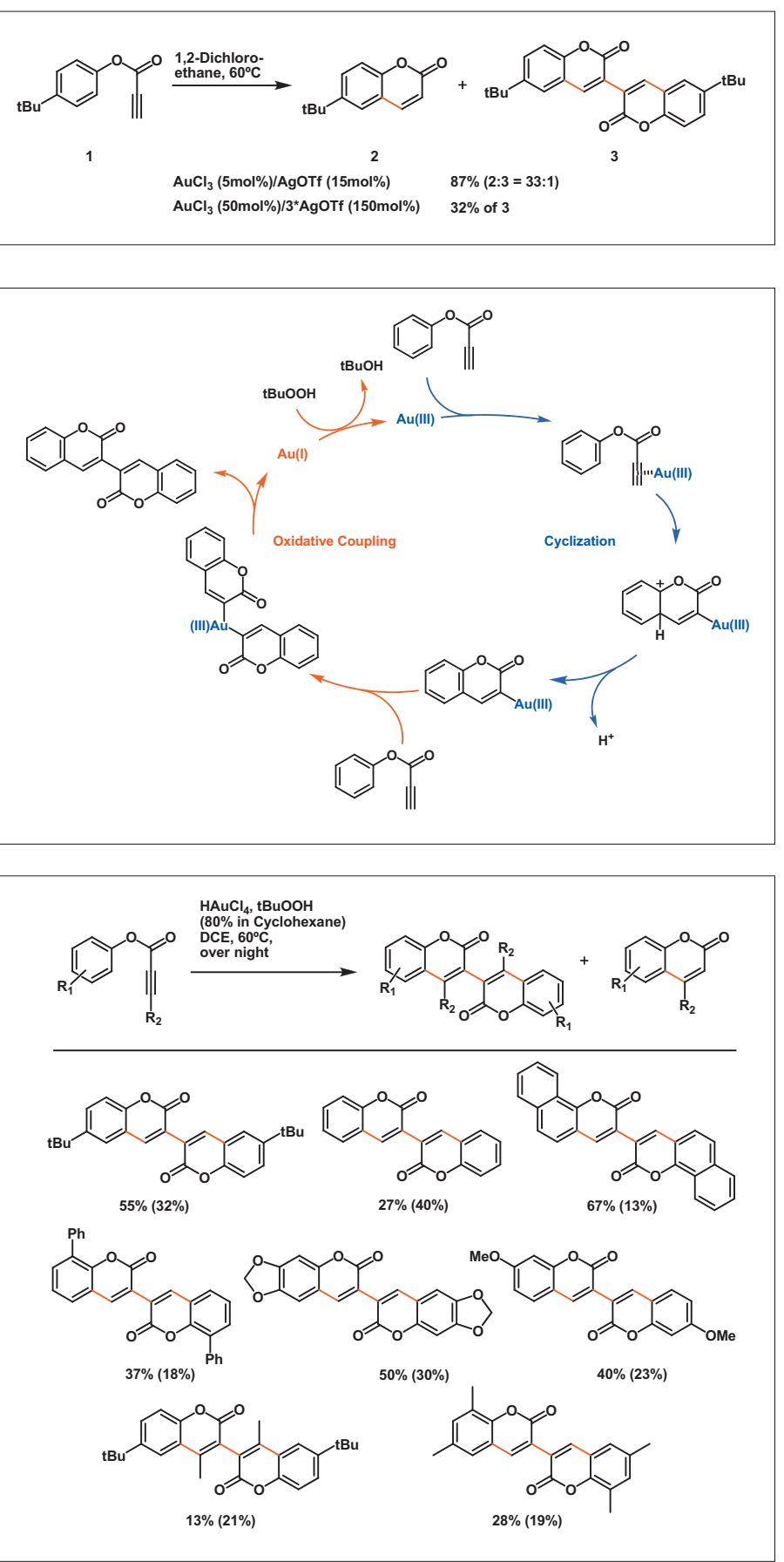

is the first example of a catalytic domino process, where the Au-catalyst acts as a $\pi$-Lewis acid and also promotes an oxidative coupling reaction.

The reaction can be done with a variety of substrates which are easily accessible in two operations from commercial available starting material (Scheme 3). However, the method is not applicable to electron deficient aryl groups and tethers other then ester moieties. Nevertheless, the potential of this catalytic domino reaction is demonstrated and can be applied for the preparation of various 2,2'-biscoumarins, that are of interest as photostable UV-dyes.

[1] a) L. F. Tietze, Chem. Rev. 1996, 96, 115; b) L.F. Tietze, G. Brasche, K. Gericke, 'Domino Reactions in Organic Synthesis', Wiley-VCH, Weinheim, 2006.

Scheme 1. Cyclization of alkynyl aryl esters using catalytic and substoichiometric amounts of $\mathrm{Au}($ (II).

Scheme 2. Proposed catalytic cycle for the domino reaction: cyclization/oxidative coupling

Scheme 3. Substrate scope of the Aucatalyzed domino cyclization oxidative coupling; yields of monomers in parentheses.
[2] Z. Shi, C. He, J. Org. Chem. 2004, 69, 3669.

[3] a) H. A. Wegner, Chimia 2009, 63, 44; b) P. Garcia, M. Malacria, C. Aubert, V. Gandon, L. Fensterbank, Chem. Cat. Chem. 2010, 2, 493.

[4] H. A. Wegner, S. Ahles, M. Neuenburg, Chem. Eur. J. 2008, 14, 11310. 


\section{Short Peptides for Organocatalytic Reactions}

\section{Helma Wennemers}

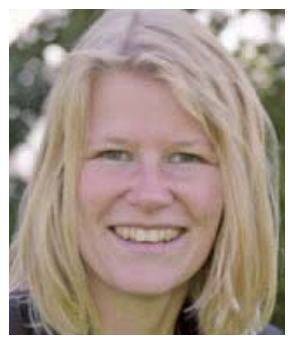

The Wennemers group is engaged in using the large molecular diversity provided by peptides for the development of efficient catalysts. Since the many degrees of rotational freedom of short-chain peptides render the rational design challenging, the group initiated the research program by developing the combinatorial screening method of 'catalyst-substrate co-immobilization' which enables the detection of catalysts for essentially any bimolecular reaction within split-and-mix libraries. ${ }^{[1]}$ Using this combinatorial screening method combined with rational design, the group established tripeptides of the general type H-Pro-Pro-Xaa (Xaa = amino acid with a carboxylic acid) as effective catalysts for direct aldol reactions and conjugate addition reactions. ${ }^{[2-8]}$ The peptides allow for enamine catalysis with catalyst loadings of as little as $0.1-1 \mathrm{~mol} \%$ and provide the products in high to excellent stereoselectivities. This is remarkable as other chiral amine-based organocatalysts, such as proline and its derivatives, require significantly higher catalyst loadings of 10-30 mol\%.[9] A further benefit of peptidic catalysts is the facile tuning of their activities and selectivities by small structural modifications that can be easily introduced due to the ease of peptide synthesis. Studies with structurally closely related analogues of peptide 1 demonstrated that both the secondary amine and the carboxylic acid are important for efficient catalysis and need to be in a certain relative orientation towards each other.[3a,5]

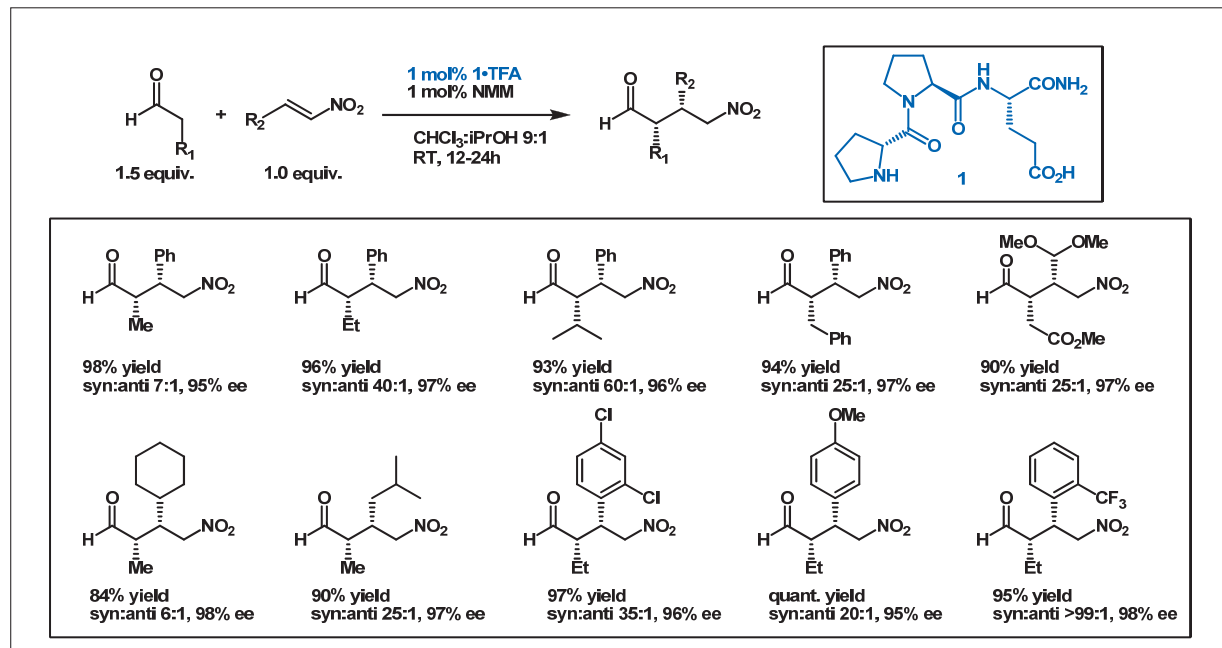

Scheme 1. Conjugate additions of aldehydes to $\gamma$-substituted nitroolefins catalyzed by peptide 1 .

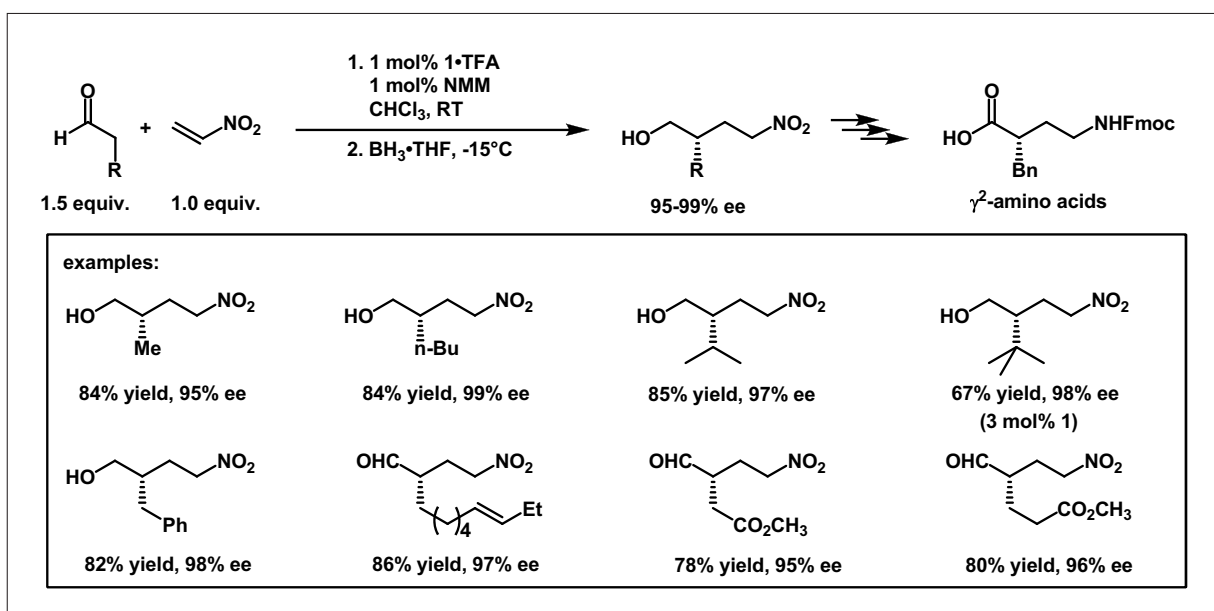

Scheme 2. Direct asymmetric catalysis route to $\gamma^{2}$-amino acids.
For example, peptide H-D-Pro-ProGlu- $\mathrm{NH}_{2}$ (1) is a highly effective catalyst for conjugate addition reactions of aldehydes to nitroolefins. ${ }^{[4-8]}$ Initial results demonstrated that in the presence of 1 mol\% of peptide $\mathbf{1}$ a broad range of aldehyde and $\beta$-substituted nitroolefin react readily to provide $\gamma$-nitroaldehydes in excellent yields and stereoselectivities (Scheme 1). ${ }^{[4-6]}$

Even the simplest of all nitroolefins, nitroethylene, reacts with aldehydes in the presence of the peptidic catalyst 1 to provide mono-substituted $\gamma$-nitroaldehydes in good yields and excellent enantioselectivities. ${ }^{[7]}$ The latter provide for a facile access to mono-substituted $\gamma$-amino acids that have previously only been accessible using chiral auxiliaries (Scheme 2).

Most recently, kinetic studies shed light onto the rate-determining steps of the peptide-catalyzed conjugate addition reactions. ${ }^{[8]}$ The studies revealed that within the proposed enamine catalysis cycle (Scheme 3 ), not the enamine formation but both the $\mathrm{C}-\mathrm{C}$ bond formation step and the hydrolysis of the iminium ion are rate limiting for the reaction.

In addition, these experiments demonstrate that the reaction rate increases by lowering the amount of water to the minimum that is generated in the enamine formation step. These insights enabled further optimization of the reaction conditions by using i) dried solvents and reagents to minimize the amount of water and ii) an excess of the nitroolefin with respect to the aldehyde. Under these conditions, the 1,4-addition reactions proceed significantly faster compared to the conditions used before (approx. threefold acceleration). Most remarkably, under these improved reaction conditions a catalyst loading of as little as $0.1 \mathrm{~mol} \%$ is still sufficient for excellent catalytic activity and stereoselectivities which is the lowest catalyst loading thus far achieved in enamine catalysis with synthetic organocatalysts. ${ }^{[8]}$

The research demonstrates that peptides are attractive asymmetric catalysts combining features that are known from natural enzymes (e.g. a certain degree of conformational flexibility to adopt to different transition states) and others that are typical for man-made synthetic catalysts (e.g. broad substrate scope).

[1] P. Krattiger, C. McCarthy, A. Pfaltz, H Wennemers, Angew. Chem. Int. Ed. 2003, 42, 1722 .

[2] a) P. Krattiger, R. Kovàsy, J. D. Revell, S. Ivan, H. Wennemers, Org. Lett. 2005, 7, 1101; b) P. Krattiger, R. Kovàsy, J. D. Revell, H. Wennemers, QSAR Comb. Sci. 2005, 24, 1158.

[3] a) J. D. Revell, H. Wennemers, Adv. Synth. Catal. 2008, 350, 1046; b) J. D. Revell, H. Wennemers, Tetrahedron 2007, 63, 8420; c) C. Aprile, F. Giacalone, M. Gruttadauria, A. Mossuto Marculescu, R. Noto, J. D. Revell, H. Wenne- 


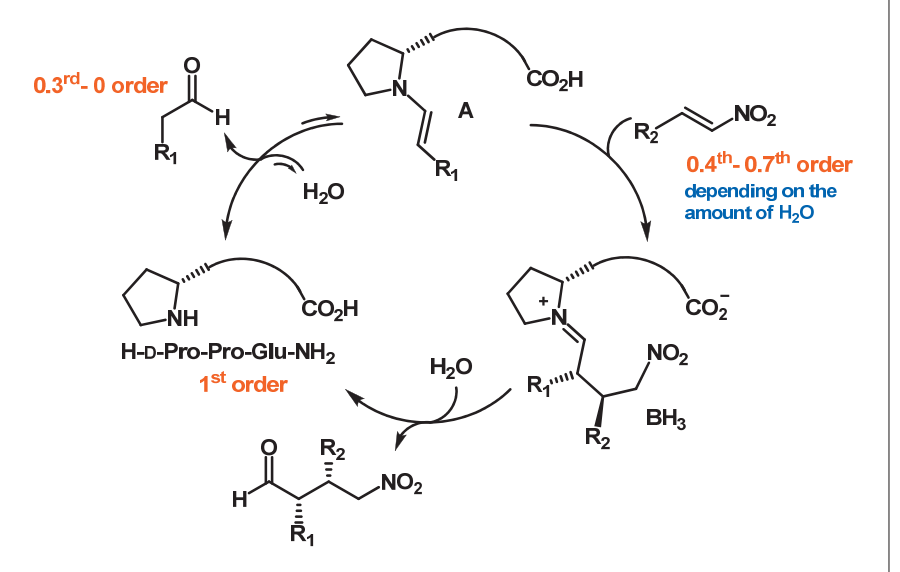

Scheme 3. Proposed catalytic cycle with rate orders.

mers, Green Chemistry 2007, 9, 1328; d) J. D. Revell, D. Gantenbein, P. Krattiger, H. Wennemers, Biopolymers (Pept. Sci.) 2006, 84, 105.

[4] M. Wiesner, J. D. Revell, H. Wennemers, Angew. Chem. Int. Ed. 2008, 47, 1871.

[5] M. Wiesner, M. Neuburger, H. Wennemers, Chem. Eur. J. 2009, 15, 10103.

[6] M. Wiesner, H. Wennemers, Synthesis 2010 1568.

[7] M. Wiesner, J. D. Revell, S. Tonazzi, H. Wennemers, J. Am. Chem. Soc. 2008, 130, 5610.

\section{From Bioorganic Chemistry to Catalysis}

\section{Wolf-D. Woggon and Antoinette Chougnet}

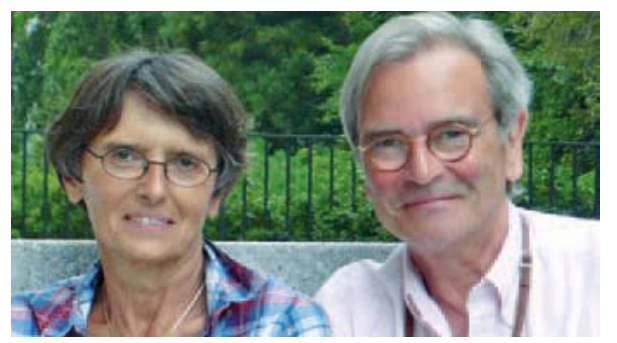

routes for the synthesis of vitamin E compounds. ${ }^{[3]}$

The experience gained by preparing supramolecular carotenoid-binding bis- $\beta$ cyclodextrin metal complexes led to the design and synthesis of ruthenium complexes 1 and $2 .{ }^{[4]}$ These complexes are reminiscent of metalloenzymes as they contain a hy- drophobic binding site of substrates and a metal cofactor for chemical reactivity. Ruthenium complex $\mathbf{1}$, attached to the primary face of $\beta$-cyclodextrin and $\mathbf{2}$ modified at the secondary face, are excellent catalysts for enantioselective hydrogen transfer reactions to aromatic and aliphatic ketones (see two examples in Scheme 1). The results with aliphatic ketones are unprecedented as most of the other catalytic systems are only efficient using aromatic substrates. ${ }^{[5]}$

From the work on the enzyme tocopherol cyclase (see article on Bioorganic and Bioinorganic Chemistry, page 846) a rather short biomimetic synthesis of $\alpha$ tocopherol (3) evolved ${ }^{[6]}$ and subsequently three new routes to the biologically most important vitamin E compound were developed. ${ }^{[7]}$ The key steps of two sequences ${ }^{[7 b, c]}$ employ organocatalytic reactions such as the Shi epoxidation, of a suitably protected phytylhydroquinone $\mathbf{4}$ using catalyst 5 and a proline-catalyzed domino-aldol-oxaMichael reaction of phytal $\mathbf{6}$ and salicylaldehyde 7 in the presence of $8(30 \mathrm{~mol} \%)$ (Scheme 2).

As an alternative, a Mitsunobu reaction was used to connect phenols $\mathbf{9}$ and $\mathbf{1 0}$ under inversion of configuration with the chiral $\alpha$-hydroxyester 11. The resulting phenolethers $\mathbf{1 2}$ and $\mathbf{1 3}$ were transformed into $\alpha$-tocopherol (3) displaying 94\% de (Scheme 3).[7a]

In the course of these synthetic approaches towards $\alpha$-tocopherol the activation of the phytyl double bond by metal complexes was a serious option (see 14, Fig. 1). However, in contrast to triflate salts of $\mathrm{Cu}$ and $\mathrm{Ag}$ the Lewis acidity of various chiral complexes of $\mathrm{Cu}$ and $\mathrm{Ag}$ proved to be too weak to activate the double bond.
The synthesis of catalytically competent enzyme models steered the focus of Woggon's research towards the development of catalysts for enantioselective hydrogen transfer reactions ${ }^{[1]}$ and $\mathrm{C}-\mathrm{C}$ bond formations ${ }^{[2]}$ leading inter alia to several new

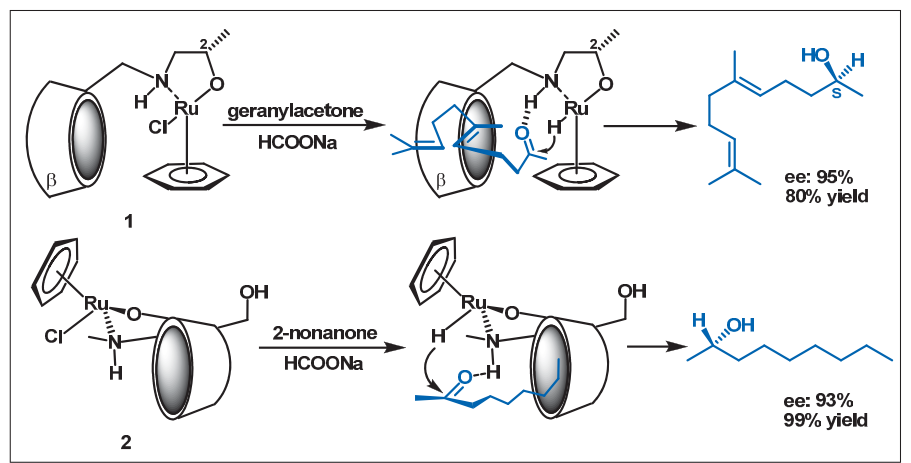

Scheme 1. Hydrogen transfer reaction to aliphatic ketones using catalysts 1 and $\mathbf{2}$; tentative structures of ruthenium hydride substrate inclusion complexes are shown.

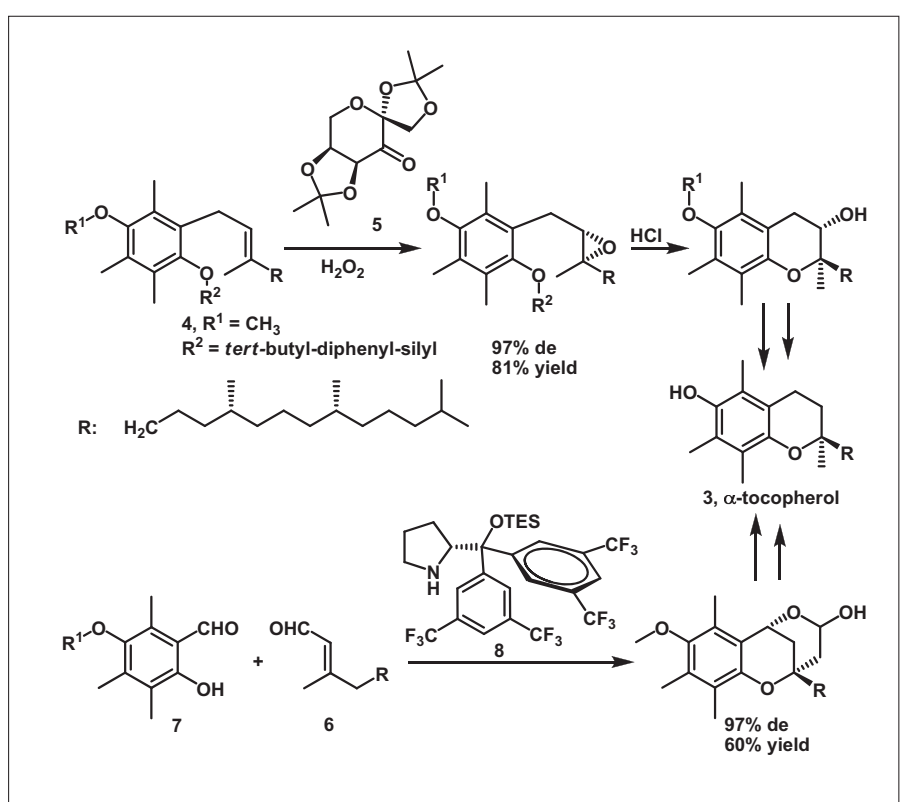

Scheme 2. Organocatalytic key steps for the synthesis of $\alpha$-tocopherol (3). 


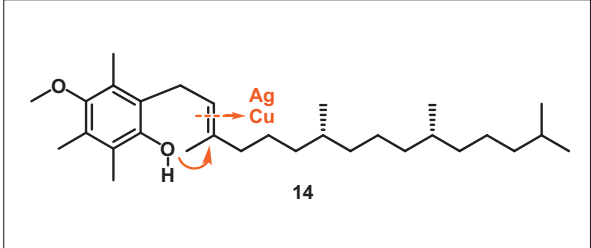

Fig. 1. Activation of the phytyl double bond for ring closure.

Nevertheless an interesting application for one of the copper (II) complexes was found: the C1-symmetric complex $\mathbf{1 5}$ is a versatile enantioselective catalyst ( 5 mol\%) for the nitro aldol reaction (Henry reaction) between nitro methane and various aromatic and aliphatic aldehydes and corresponding $\mathrm{N}-\mathrm{Boc}$ imines (Scheme 4). ${ }^{[2]}$

X-ray crystallography of C1-symmetric $\mathbf{1 5}$ revealed an unusual single-stranded M left-handed helix stabilized through hydrogen bonding between the non-coordinating pyridine and the $\mathrm{N}-\mathrm{H}$ adjacent to the phenolate and by $\pi$-stacking of the pyridines. The residual acetate is believed to be exchanged for the components of the Henry reaction. At present C1-symmetric $\mathrm{Cu}$ complexes such as $\mathbf{1 5}$ are investigated for applications to diastereoselective and enantioselective Henry reactions.

\section{Acknowledgement}

Financial support of these research projects by the Swiss National Science Foundation, F. Hoffmann-La Roche AG and DSM is gratefully acknowledged.

[1] W.-D. Woggon, Curr. Org. Chem. 2010, 14, 1362.

[2] G. Zhang, E. Yashima; W.-D. Woggon, Adv. Synth. Catal. 2009, 351, 1255.

[3] A. Chougnet, K. Liu, W.-D. Woggon, Chimia 2010, 64, 303 .

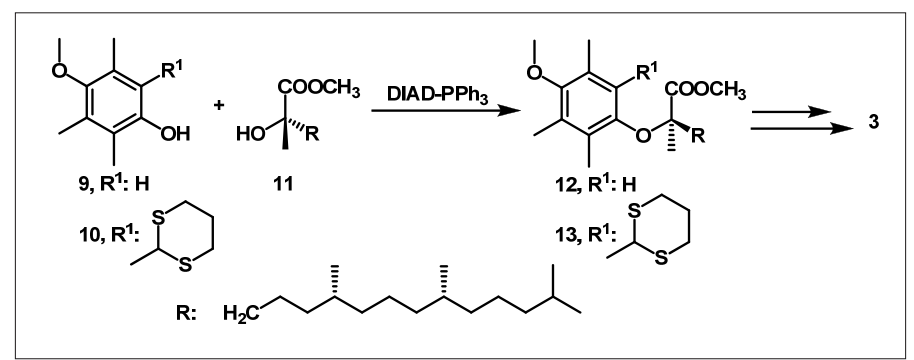

Scheme 3. Synthesis of 3 via a Mitsunobu reaction.
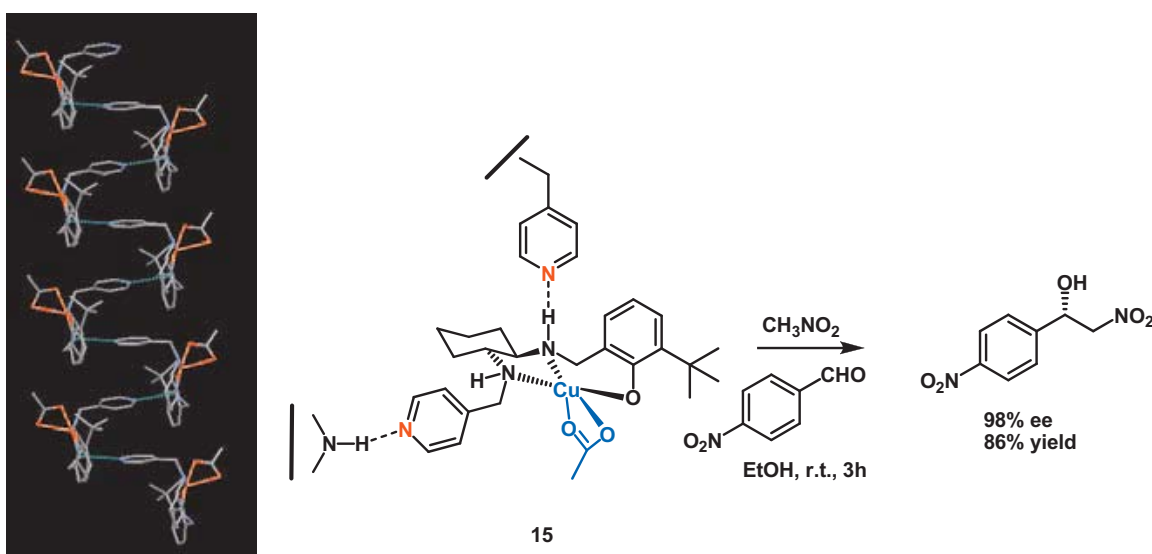

Scheme 4. A new Cu(II) catalyst for enantioselective Henry reactions.

[4] A. Schlatter, W.-D. Woggon, Wolf-D., Adv Synth. Catal. 2008, 350, 995; A. Schlatter, M. K. Kundu, W.-D. Woggon, Wolf-D., Angew. Chem. Int. Ed. 2004, 43, 6731.

[5] M. T. Reetz, X. Li, J. Am. Chem. Soc. 2006, 128, 1044 -1045; T. Ohkuma, C. A. Sandoval, R. Srinivasan, Q. Lin, Y. Wei, K. Muniz, R. Noyori, J. Am. Chem. Soc. 2005, 127, 8288.

6] J. Chapelat, A. Chougnet, W.-D. Woggon, Eur J. Org. Chem. 2009, 13, 2069; C. Grütter, E. Alonso, A. Chougnet, W.-D. Woggon, Angew. Chem. Int. Ed. 2006, 45, 1126.

[7] a) U. Hengartner, A. Chougnet, K. Liu, W.D. Woggon, Chem. Eur. J. 2010, 16, 1306; b)
K. Liu, A. Chougnet, W.-D. Woggon, Angew. Chem. Int. Ed. 2008, 47, 5827; c) J. Chapelat, A. Buss, A. Chougnet, W.-D. Woggon, Org. Lett. 2008, 10, 5123.

Received: October 11, 2010 